\title{
CORRELATION OF BRONCHIAL BRUSHING CYTOLOGY WITH BRONCHIAL BIOPSY IN DIAGNOSIS OF LUNG CANCER
}

\author{
Eva Piya ${ }^{1}$, Geeta Sayami ${ }^{2}$, Brajendra Srivastava ${ }^{3}$ \\ ${ }^{1}$ Departmenof Pathology. Shree Birendra Hospital, '2Department of Pathology. Tribhuvan University Teaching Hospital, \\ ${ }^{3}$ Department of Chest Diseases, Shree Birendra Hospital
}

\begin{abstract}
Introduction: Lung cancer is one of the leading cause of death in western countries and is the second most common malignancy in Nepal. Fiberoptic bronchoscopy has an excellent result in diagnosis of lung cancer when combined with brushing cytology \& biopsy. This prospective study was conducted at Tribhuvan University Teaching Hospital over the period of one year with the aim to correlate brushing cytology with biopsy in diagnosis of bronchoscopically visible lung cancer.
\end{abstract}

Method: A total of 62 cases were included in this study on whom bronchoscopy was performed in endoscopy unit. Bronchial brushing, biopsy specimens were collected \& processed accordingly.

Results: Out of 62 cases, 53 were found to be malignant and 9 were inflammatory lesions. Thus, cytohistological correlation was done in 53 malignant cases. There were 38 male and 15 were female with a mean age of 54 years. The male:female ratio was 2.5:1.

The most common type of carcinoma was squamous cell carcinoma (64.2\%), followed by

adenocarcinoma (18.8\%), small cell carcinoma(13.2\%), large cell carcinoma (1.9\%), carcinoid tumor(1.9\%). Sensitivity of the bronchial brushing was $94.6 \%$ while that of biopsy was $91.3 \%$.

Conclusion: Bronchial brushing cytology has better detection rate than biopsy in this study. However combination of these modalities gives higher detection rate for bronchoscopically visible tumor. Therefore, bronchial brush cytology should be performed whenever possible in all suspected cases of lung cancer.

Key words: Bronchial brushing cytology, bronchial biopsy, lung cancer.

\section{INTRODUCTION}

Lung cancer is the second most common malignancy after gastric malignancy in developing countries like Nepal and is the most common malignancy in developed countries. ${ }^{1}$ In records the incidence in Nepal has increased from $5.3 \%$ in 1989 to $7.3 \%$ in 1992 to $17.5 \%$ in $1996 .{ }^{1}$ The increasing incidence could be due to increase in smoking habit, change in life styles of the people, increased environmental pollution, and at the same time, due to availability of different modern diagnostic modalities to detect lung cancer e.g. bronchoscopy, biopsy brush cytology, sputum cytology, transbronchial lung biopsy, CT scan, MRI, and increase awareness of people about the alarming disease. ${ }^{2}$ There are different techniques for detection of lung cancers. Each is important but not

\author{
Correspondence: \\ Lt. Col. Dr Eva Piya \\ Department of Pathology, Shree Birendra Hospital. \\ E-mail: evapiya@yahoo.com \\ Cell No.: 9851079432
}


sufficient on its own. Bronchoscopy is a process of direct visualization of the tracheobronchial tree. With the development of flexible bronchoscope this has become an outpatient procedure. The bronchoscopist is able to identify not only the endobronchial lesions in patients with endobronchial pathology, samples from airway lesions can be collected by several methods like bronchial brushing, aspiration, bronchial biopsies, transbronchial lung biopsies, transbronchial needle aspiration and hence define the pathology with much more accuracy. ${ }^{3}$

Bronchoscopy, followed by brushing and biopsy, in clinically and radiologically suspected cases, is the main diagnostic procedure in our contest. ${ }^{4}$ Brushing cytology is considered as an effective tool to diagnose this condition as it covers wider area $(2 \mathrm{~cm})$ compared to less than $5 \mathrm{~mm}$ by forceps \& it is easy to obtain brushing cytology sample when biopsy is difficult in certain anatomical location of the lesions. ${ }^{3}$ It is a highly sensitive procedure because the specimen is directly obtained from the lesion \& without contamination from saliva or nasopharyngeal secretion. ${ }^{5}$ Bronchoscopy has got a diagnostic yield of more than $90 \%$ when combined with brushing cytology \& biopsy. ${ }^{6}$

\section{METHOD}

The study was carried out prospectively at the Department of Pathology \& Endoscopic unit, Tribhuvan University Teaching Hospital, Maharajganj (TUTH) over the period of one year. All the cases, clinically \& radiologically suspected of lung cancer, undergoing bronchoscopy, in which both brush cytology and bronchial biopsy done, were included in this study. Peripheral lung cases, where biopsies \& brushings are obtained by other means, e.g. TBLB (transbronchial lung biopsy), ultrasound guided or CT guided fine needle aspiration cytology were excluded from this study.

Bronchoscopy was performed with flexible bronchoscope (Olympus type 10) in endoscopy department. Patients with normal bronchoscopic findings were excluded from study at this stage. Brushing cytology specimens were collected. The brush along with adhered cells was smeared on glass slides \& fixed immediately in 95\% propanolol and stained with Papaniculaou stain after fixation.Bronchial biopsy specimens were collected. The specimens were fixed with $10 \%$ formal saline for 1 day \& processed in automated tissue processor and sections were prepared and stained with haematoxylin \& eosin stain.

\section{RESULTS}

A total of 62 cases met the criteria for selection whose bronchoscopic biopsies, brushing specimens were collected over the period of 1 year. Out of 62 cases, of which 53 were found to be malignant. Remaining 9 cases were inflammatory lesions, thus, cytohistological correlation was conducted only in 53 malignant cases. The most common was the squamous cell carcinoma (64.2\%), followed by adenocarcinoma (18.8\%), small cell carcinoma(13.2\%), carcinoid tumor(1.9\%) \& large cell carcinoma (1.9\%).

There were 38 male \& 15 female with male to female ratio 2.5. The average age of the cases ranged from 38 years to 78 years, the mean age being 54 years. Differnet types of bronchogenic carcinomas diagnosed by brush cytology are tabulated (Table 1 ) .

Biopsies alone could detect $90.6 \%$ of all the cases. Among them, squamous cell carcinoma comprised $64.1 \%$, adenocarcinoma $13.2 \%$, \& small cell carcinoma $13.2 \%$. It could not detect adenocarcinoma (5.6\%) carcinoid tumor(1.9\%) \& large cell carcinoma(1.9\%). Both revealed only necrotic tissue in biopsies.

\section{Correlation of bronchial brushing cytology and biopsy}

Both bronchial biopsy and brushing cytology were positive for malignancy in 47cases. Only brushing cytology was positive for malignancy in 4 cases. Only biopsy was positive in 2 cases. Out of 34 cases of squamous cell carcinoma, 32 cases were detected both by biopsies \& brushing cytology \& were well correlated. In 2 cases it was diagnosed only by biopsy while brushing cytology were negative for malignancy. Out of 10 cases of adenocarcinima, 7 were detected by both biopsy as well as brushing cytology. However, 3 cases of adenocarcinomas were detected by brushing cytology \& biopsy was negative for malignancy. All cases of small cell carcinoma was detected by both biopsy as well as brushing cytology and all were well correlated. Each case of carcinoid tumor \& large cell carcinoma were detected by brushing cytology \& biopsies were negative for malignancy for both of them.

The sensitivity of the procedure of bronchial brushing was $94.6 \%$ and that of bronchial biopsy was $91.3 \%$. When both biopsy $\&$ brush cytology were combined, they could diagnose all 53 malignant cases. 
Table no. 1: Different types of bronchogenic carcinoma

\begin{tabular}{|l|l|}
\hline $\begin{array}{l}\text { Histological types of } \\
\text { carcinomas }\end{array}$ & Number of cases (\%) \\
\hline Squamous cell carcinoma & $34(64.2 \%)$ \\
\hline Adenocarcinoma & $10(18.8 \%)$ \\
\hline Small cell carcinoma & $07(13.2 \%)$ \\
\hline Large cell carcinoma & $01(1.9 \%)$ \\
\hline Carcinoid tumor & $01(1.9 \%)$ \\
\hline Total & $53(100 \%$ \\
\hline
\end{tabular}

Table no.2: Types of carcinomas diagnosed by bronchial brush cytology

\begin{tabular}{|l|l|l|}
\hline $\begin{array}{l}\text { Histological types of } \\
\text { carcinomas }\end{array}$ & Number & Percentage \\
\hline $\begin{array}{l}\text { Squamous cell } \\
\text { carcinoma }\end{array}$ & 32 & $60.3 \%$ \\
\hline Adenocarcinoma & 10 & $18.8 \%$ \\
\hline Small cell carcinoma & 07 & $13.2 \%$ \\
\hline Carcinoid tumor & 01 & $1.8 \%$ \\
\hline Large cell carcinoma & 01 & $1.8 \%$ \\
\hline $\begin{array}{l}\text { Negative for } \\
\text { malignancy }\end{array}$ & 02 & $3.7 \%$ \\
\hline Total & 53 & $100 \%$ \\
\hline
\end{tabular}

Table no.3: Types of carcinomas diagnosed by bronchial biopsy

\begin{tabular}{|l|l|l|}
\hline $\begin{array}{l}\text { Histological types of } \\
\text { carcinomas }\end{array}$ & Number & Percentage \\
\hline $\begin{array}{l}\text { Squamous cell } \\
\text { carcinoma }\end{array}$ & 34 & $64.1 \%$ \\
\hline Adenocarcinoma & 07 & $13.2 \%$ \\
\hline Small cell carcinoma & 07 & $13.2 \%$ \\
\hline Carcinoid tumor & 0 & $0 \%$ \\
\hline Large cell carcinoma & 0 & $0 \%$ \\
\hline Negative for malignancy & 5 & $9.5 \%$ \\
\hline Total & 53 & $100 \%$ \\
\hline
\end{tabular}

Table no. 4: Comparison of bronchial brush cytology with biopsy

\begin{tabular}{|l|l|l|l|}
\hline & $\begin{array}{l}\text { Biopsy } \\
\text { positive }\end{array}$ & $\begin{array}{l}\text { Biopsy } \\
\text { negative }\end{array}$ & Total \\
\hline Brushing positive & 46 & 5 & 51 \\
\hline Brushing negative & 2 & 0 & 2 \\
\hline Total & 48 & 5 & 53 \\
\hline
\end{tabular}

\section{DISCUSSION}

Lung cancer is the second most common malignancy after gastric malignancy in Nepal. ${ }^{1}$ The increase number of lung cancer deaths is mainly because it is detected at a late stage. ${ }^{4}$ Timely detection of the disease plays a pivotal role in the management \& for the long term survival of the patients. Bronchial brushing cytology is considered as an effective diagnostic tool for this condition. Though it is inferior to bronchial biopsy in histological typing, it is quite safe, less invasive, economical \& provide quick results as compared to bronchial biopsy. ${ }^{7,8}$ It is highly sensitive \& specific procedure as specimen is directly obtained from the lesion without contamination of saliva or nasopharyngeal secretion. Bronchoscopy has a diagnostic yield of more than $90 \%$ when combined with bronchial cytology and biopsy.

In this study, the most common tumor was squamous cell carcinoma $64.2 \%$, followed by adenocarcinoma $18.8 \%$, small cell carcinoma $13.2 \%$, large cell carcinoma $1.9 \%$ carcinoid tumor $1.9 \%$ In 46 cases, brushing cytology were well correlated with biopsy which was taken as a gold standard. There were no cytologically false positive cases. This tallies with the study conducted by Sayami G et al, according to which squamous cell carcinoma was the most common one comprising $64.3 \%$, followed by adenocarcinoma $17.4 \%$, small cell carcinoma 15.4\%, large cell carcinoma $2 \%$ carcinoid tumor $0.2 \%$, bronchioalveolar carcinoma $0.2 \%$ and muco epidermoid carcinoma $0.2 \%(9)$.

Brushing had an excellent detection rate for all the tumor types in this study. It detected $94.1 \%$ of squamous cell carcinoma, $100 \%$ of adenocarcinoma, $100 \%$ of small cell carcinoma, carcinoid and large cell carcinoma. While biopsy had better detection rate in case of squamous cell carcinoma $(100 \%)$ and small cell carcinoma but had low detection rate in other types of lung cancers, such as of adenocarcinoma, and could not detect both large cell carcinoma as well as carcinoid tumor. Both the cases showed necrotic tissue on histological sections as biopsies were taken from superficial necrotic slough and could not be repeated due to bleeding. Also in peripheraly located tumor, the biopsies were difficult to obtain as tumors were difficult to access.

Detection rate of the brushing cytology was $94.2 \%$ versus $92.4 \%$ by biopsy. It is because brushing covers the wide area than biopsy and a significant amount of material can be obtained. This finding tallies with the study done in TUTH, according to which brushing cytology had better detection rate than biopsies due to several technical difficulties e.g. stenosis, bleeding, peripheral location of tumor, etc. ${ }^{4}$

M Matsuda et al observed that bronchial brushing had better detection rate (90.3\%) than biopsy(64.8\%) . Combination of both modalities yielded highest incidence 
of positive diagnosis( 93.7\%), which very well correlates with our results. ${ }^{10}$ According tothe study done by Ashok $\mathrm{K}$ et al, brushing had better detection rate than biopsy $72 \%$ versus $69 \% .^{11}$

However in many studies biopsy had a better detection rate. In one study done in Nepal Medical college, lung cancer detection rate of bronchial biopsy was $92.2 \%$, while brushing could detect only $65.2 \%$ of the cases. ${ }^{12}$ Similarly another study conducted by KA Gaber et al, biopsy had a better detection rate than brushing cytology ie.79.4\% versus $74.5 \% .^{13}$ which is also comparable to the study conducted by Saita et al which showed higher sensitivity of bronchial brushing( $85.5 \%$ ) than the biopsy. ${ }^{14}$

\section{CONCLUSION}

Lung cancer is one of the major causes of morbidity \& mortality in developing countries. Bronchial brushing cytology is an inexpensive, effective diagnostic tool in detection of lung cancer and it can diagnose lung cancers where bronchoscopic biopsy is technically not feasible or not interpretable. It is highly sensitive procedure. It has insignificant false positive or negative results, so at advanced stage it can be the only important \& time saving preoperative diagnostic tool in our contest .It had better detection rate than biopsy. However combination of these modalities gives higher detection rate for bronchoscopically visible tumor.

\section{REFERENCES}

1. Shrestha HG, Dali S, Sayami G et.al, Present cancer scenario \& its changing pattern at TUTH. JNMA.1997;35:45-51.

2. Juan Rosai.Surgical Pathology;8th edition, 1995:372-3.

3. Shure D. Radiologically occult endobronchial obstruction in bronchogenic carcinoma. Amer J Med. 1991;91:19-22.

4. Sayami G. Sayami P. Bronchial brushing cytology in suspected lung cancer. JNMA.1993;31:132-7.

5. Chokhani R. Lung cancer diagnosis by bronchofibroscopy in a chest clinic Kathmandu. NMCJ. 1998;1:25-6.

6. Kawaraya M, Gemba K, Ueoka H, Nishii K, Kodani T. Evaluation of various cytological examinationa by bronchoscopy in diagnosis of peripheral lung cancer. British Journal of Cancer. 2003;89:1885-88.

7. Gaber KA. Cytologic examination of whole endobronchial brush in bronchoscopic diagnosis of lung cancer. Respiratory Medicine. 2002;96(4):259-61.

8. Thomas LP. Sputum cytology for early diagnosis of lung cancer. Current Opinion in Pulmonary Medicine. 2003;19(40):30912.

9. Sayami G. Diagnosis \& Histochemical patterns of lung cancer in Nepal: An analysis of 527 cases; JNMA. 1997;35:39-44.

10. Jones AM, Hanson IM, Armstrong GR. Value and accuracy in addition to histology in the diagnosis of lung cancer at flexible bronchoscopy. Respiratory Medicine. 2001;95(5):374-8.

11. Ashok K, Tanwani, H Anwar Ul. correlation of bronchial brushing and biopsy in lung lesions. Pakistan J Med res. 2000;39(3)1:15-20.

12. Ramesh C, Prakrita Bhushan P, Devkota KC. Clinical \& Histocytological Profile of 200 consecutive Video Bronchoscopies. Nepal Medical college Journal 2002;4(2):64-67.

13. Gaber KA.Cytologic examination of whole endobronchial brush in bronchoscopic diagnosis of lung cancer. Respiratory Medicine. 96;4:564-65.

14. Saita S. Bronchial brushing biopsy: A comparative evaluation in diagnosing visible lesions .Eur.J.Cardithoracic Surg.1990;4(5):270-72. 